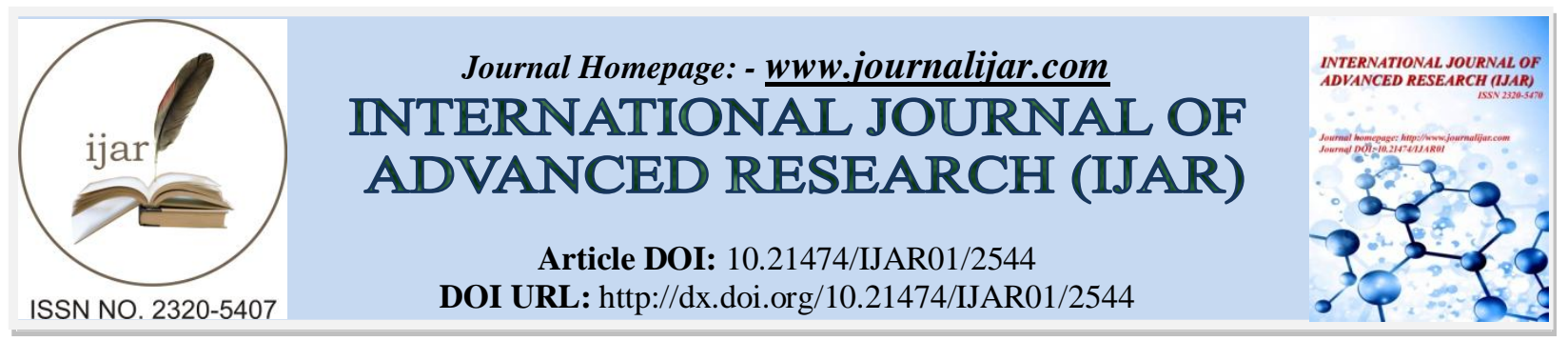

RESEARCH ARTICLE

\title{
OPEN REDUCTION AND INTERNAL FIXATION OF TRIMALLEOLAR ANKLE FRACTURE DISLOCATION- A CASE REPORT.
}

Dr. Ghaniuzzoha Asadi* and Dr.Abhijit More.

\section{Manuscript Info \\ Manuscript History \\ Received: 25 October 2016 \\ Final Accepted: 23 November 2016 \\ Published: December 2016}

Key words:-

Ankle fracture, Bimalleolar,

Trimalleolar, Union.

\section{Abstract}

Ankle fracture is a very common type of fracture frequently encountered in orthopaedic practice.Most ankle fractures are isolated malleolar fracture,accounting for two-thirds of fracture,with bimalleolar fractures occurring in one fourth of patients and trimalleolar fracture occurring in remaining 5-10\% cases.Trimalleolar fracture involves fracture of medial malleolus, fibula and posterior lip of articular surface of tibia associated with subluxation or dislocation of tibiotalar joint.Main aim of treatment of ankle fractures is anatomical ankle joint restoration and in majority of the cases it is achieved by open reduction and internal fixation. Trimalleolar fracture require open reduction more often than any other type of ankle fracture.The result of treatment of trimalleolar ankle fracturedislocation usually are not as good as the results obtained for bimalleolar fracture.We report a case of open reduction and internal fixation of trimalleolar ankle fracture-dislocation in a young patient with excellent outcome in terms of function and union .

Copy Right, IJAR, 2016,. All rights reserved.

\section{Introduction:-}

Ankle fractures is a very common type of fracture managed by orthopedic surgeon.Incidence of ankle fractures is approximately 187 fractures per 100,000 people each year.Increased body mass index is considered a risk factor for sustaining an ankle fracture[1].Most ankle fractures are isolated malleolar fractures,accounting for two-thirds of fracture, with bimalleolar fracture occurring in one fourth of patients and trimalleolar fracture occurring in remaining $5 \%$ to $10 \%$ [2].Lauge-Hansen classified ankle fractures based on mechanism of injury into four groups.Most common mechanism is supination-eversion followed by less common mechanisms supination-adduction,pronationabduction \& pronation-external rotation[2].

Trimalleolar fracture involves fracture of medial malleolus, fibula and posterior lip of articular surface of tibia associated with subluxation or dislocation of tibiotalar joint.Main aim of treatment of ankle fractures is anatomical ankle joint restoration and in majority of the cases it is achieved by open reduction and internal fixation.Trimalleolar fracture require open reduction more often than any other type of ankle fracture.The result of treatment of trimalleolar ankle fracture-dislocation usually are not as good as the results obtained for bimalleolar fracture[3]. We report a case of open reduction and internal fixation of trimalleolar ankle fracture-dislocation in a young patient with excellent outcome in terms of function and union . 


\section{Case report:-}

25 year old male presented to orthopaedic casualty with history of road traffic accident followed by pain and swelling of left ankle.Skin and soft tissue was swollen but not breached.Plain radiograph of Ankle mortise and lateral views taken.A diagnosis of trimalleolar ankle fracture dislocation made[Fig 1 \& 2] and patient was admitted with below knee posterior slab.Open reduction and internal fixation was planned for the patient.

Under Spinal Anaesthesia,under tourniquet control routine posterolateral approach used for fibula first.After exposing fracture site of fibula,fracture reduced and fixed with 8 hole semitubular plate and screws.Medial malleolus exposed with anteromedial incision.Periosteum removed off fracture site.Fracture reduced and compressed with one $4 \mathrm{~mm}$ cannulated cancellous screw.Posterior lip of intra-articular tibial plafond was reduced with reduction forceps and reduction confirmed under fluoroscopy. With reduction in hold 2 cannulated cancellous screws of $4 \mathrm{~mm}$ passed anteroposteriorly to achieve compression at fracture site. Anatomical restoration of ankle joint confirmed under fluoroscopy in mortise view and lateral view.Syndesmotic screw was placed through fibula plate from fibula into tibia.Articular congruity and syndesmotic stability confirmed under fluoroscopy[Fig 3 \& 4].Incision closed in layers.Post-operatively below knee posterior slab applied.

Patient was kept non-weight bearing for 6 weeks.At 6 weeks slab was removed and PTB Cast applied and patient was made to partially weight bear.At 12 weeks PTB cast and syndesmotic screw removed and patient was continued to fully weight bear.At 6 months follow up radiology showed complete bony union with excellent restoration of articular congruity of ankle joint[Fig $5 \& 6$ ].Clinically patient also showed excellent function of ankle joint.
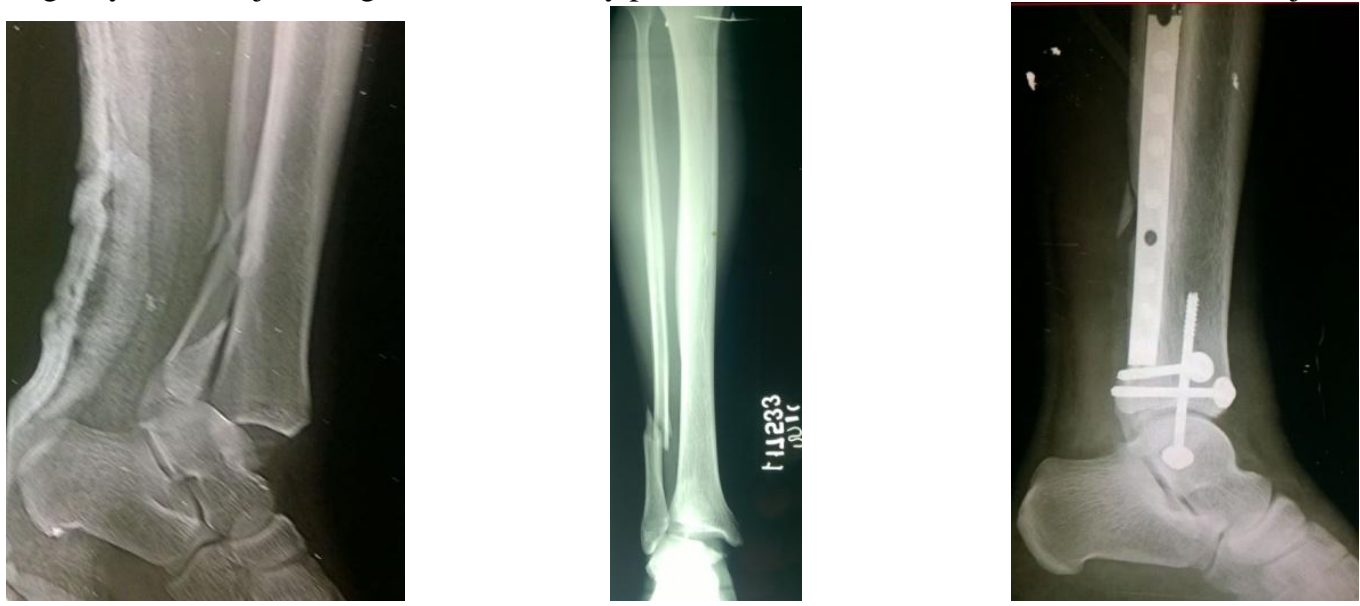

Fig 1:- Preoperative Xray lateral view. Fig 2- Pre-operative Xray Mortise view. Fig 3-Immediate post-operative
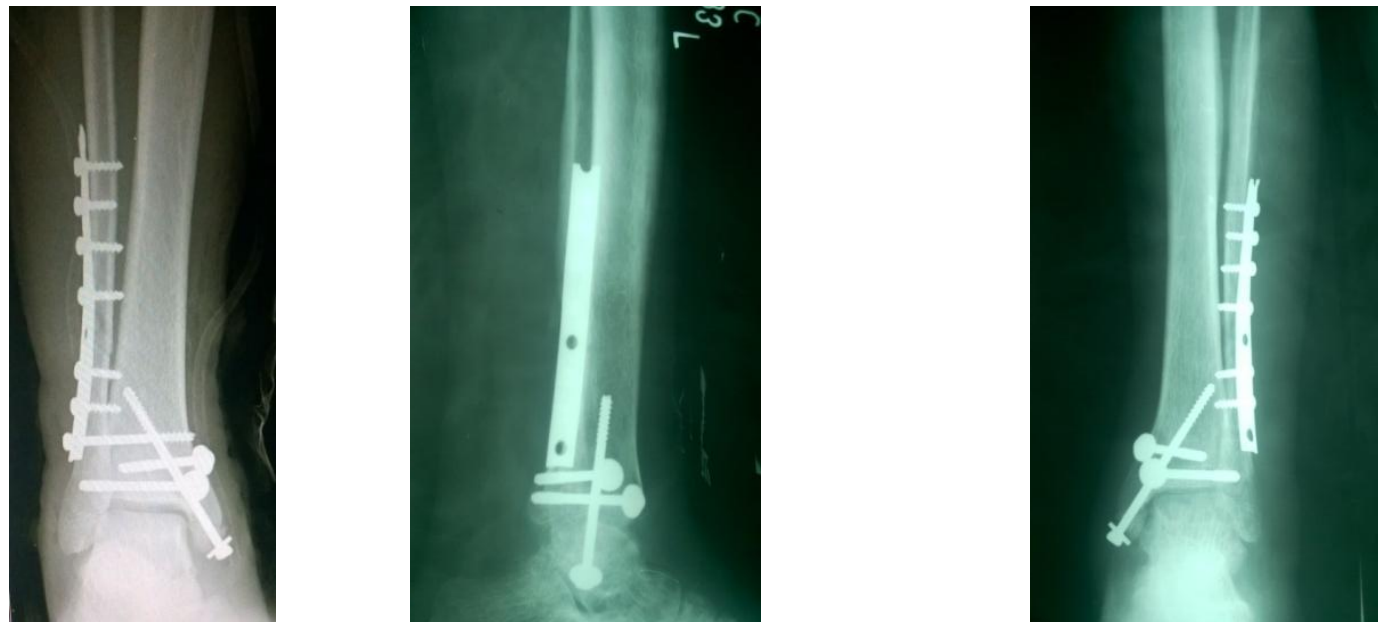

Fig 4:- Immediate post-operative Fig-5 \& 6- At 6 month follow up Xray showing completely united fracture. 


\section{Conclusion:-}

Open reduction and internal fixation of ankle fractures offers excellent results in terms of bony union and return of function.Trimalleolar ankle fracture-dislocation though a difficult fracture to treat and outcome is variable if ankle joint properly restored intra-operatively and exquisite follow up care given ,can result into excellent outcome[4-7].

\section{References:-}

1. Egol K A, Dolan R, Koval K J.Fractures of ankle, a prospective randomized comparison of management in cast or a functional brace. J. Bone Joint Surg. Br. 2000,82:246-249.

2. Lauge-Hansen, $\mathbf{N}$. Fractures of the ankle. II. Combined experimental-surgical and experimental-roentgenologic investigation. Arch Surg 60:957-985, 1950.

3. Olerud, C., and Molander, H. Bi- and Trimalleolar Ankle Fractures Operated on With Nonrigid Internal Fixation. Clin. Orthop. 206:253-260, 1986.

4. DeSouza, L.J., Gustilo, R.B., and Meyer, T.J.: Results of Operative Treatment of Displaced External Rotation-Abduction Fractures of the Ankle. J. Bone Joint Surg., 67A: 1066-1074, 1985.

5. Hughes, J.L., Weber, H., Willenegger, H., and Kuner, E.H.: Evaluation of Ankle Fractures. Clin. Orthop. 138:111-119, 1979.

6. Johnson, E.E., and Davlin, L.B.: Open Ankle Fractures-Indications For Immediate Open Reduction and Internal Fixation. Clin. Orthop., 292:118-127, 1993.

7. Joy, G., Patzakis, M.J., and Harvey, J.P.: Precise Evaluation of the Reduction of Severe Ankle Fractures. J. Bone Joint Surg., 56A: 979-993, 1974. 